\title{
Characteristics of Americans Choosing Vegetarian and Vegan Diets for Health Reasons
}

\author{
Holger Cramer, $\mathrm{PhD}^{1,2}$; Christian S. Kessler, $\mathrm{MD}^{3,4}$; Tobias Sundberg, $\mathrm{PhD}^{2,5}$; \\ Matthew J. Leach, $\mathrm{PhD}^{2,6}$; Dania Schumann, $\mathrm{MSc}^{1}$; Jon Adams, $\mathrm{PhD}^{2}$; Romy Lauche, $\mathrm{PhD}^{2}$
}

\begin{abstract}
Objective: Examine the prevalence, patterns, and associated factors of using a vegetarian or vegan diet for health reasons in the US general population.

Design: Cross-sectional data from the 2012 National Health Interview Survey.

Participants: Nationally representative sample $(\mathrm{N}=34,525)$.

Variables Measured: Prevalence of ever use and 12-month use of vegetarian or vegan diet for health reasons, patterns of use, and sociodemographic and health-related factor associated with use.

Analysis: Multiple logistic regression analysis.

Results: Prevalence of ever use and 12-month use was $4.0 \%(\mathrm{n}=1,367)$ and $1.9 \%(\mathrm{n}=648)$, respectively. Health vegetarians and vegans were more likely aged 30-65 years, female, not Hispanic, from the Western US region, at least high school educated, chronically ill, and physically active. They were less likely to be in a relationship, overweight or obese, or smoking, or to have public or private health insurance. Among health vegetarians and vegans, $6.3 \%$ consulted with a practitioner for special diets; $26.1 \%$ followed the diet because of a specific health problem, mainly high cholesterol, overweight, hypertension, and diabetes; and $59.4 \%$ disclosed the diet to their health care provider.

Conclusions and Implications: Less than $2 \%$ of participants reported using a vegetarian or vegan diet for health reasons within the past 12 months. Despite potential benefits of plant-based nutrition, more research is warranted on the actual use and its effects and safety.
\end{abstract}

Key Words: vegetarian, vegan, diet, survey, prevalence (J Nutr Educ Behav. 2017;49:561-567.)

Accepted April 21, 2017.

\section{INTRODUCTION}

Vegetarianism is a broad term that encompasses a diverse and heterogeneous range of dietary practices. According to the Academy of Nutrition and Dietetics, a vegetarian diet is one that "does not include meat (including fowl) or sea- food, or products containing these foods, ${ }^{11}$ which varies from one that incorporates dairy products (lacto-vegetarianism) or eggs (ovo-vegetarianism) to one that avoids all flesh, dairy, and egg foods and sometimes honey (veganism). ${ }^{2}$ Several activists and influential lobby organizations in the field ${ }^{3}$ also refer to plant-

\footnotetext{
${ }^{1}$ Department of Internal and Integrative Medicine, Kliniken Essen-Mitte, Faculty of Medicine, University of Duisburg-Essen, Essen, Germany

${ }^{2}$ Australian Research Centre in Complementary and Integrative Medicine, Faculty of Health, University of Technology Sydney, Sydney, New South Wales, Australia

${ }^{3}$ Immanuel Hospital Berlin, Department for Complementary Medicine, Berlin, Germany

${ }^{4}$ Institute for Social Medicine, Epidemiology and Health Economics, Charité Medical University, Berlin, Germany

${ }^{5}$ Department of Neurobiology, Care Sciences and Society (NVS/OMV), Karolinska Institutet, Stockholm, Sweden

${ }^{6}$ School of Nursing and Midwifery, University of South Australia, Adelaide, Australia Conflict of Interest Disclosure: The authors' conflict of interest disclosures can be found online with this article on www.jneb.org.

Address for correspondence: Holger Cramer, PhD, Department of Internal and Integrative Medicine, Kliniken Essen-Mitte, Faculty of Medicine, University of Duisburg-Essen, Am Deimelsberg 34a, 45276 Essen, Germany; Phone: +(49-201) 174-25015; Fax: +(49-201) 174-25000; E-mail: h.cramer@kliniken-essen-mitte.de

(C)2017 Society for Nutrition Education and Behavior. Published by Elsevier, Inc. All rights reserved.

http://dx.doi.org/10.1016/j.jneb.2017.04.011
}

based nutrition instead of vegan nutrition. The diverse and heterogeneous range of dietary practice as well as the nonuniform use of terminology in both research and practice contributes much to the complexity of the topic. ${ }^{4}$

There are a variety of reasons for using a vegetarian or vegan diet, including moral, ethical, spiritual, or religious reasons as well as those concerning animal rights and animal welfare, ${ }^{5}$ or social or environmental concerns related to intensive animal husbandry or sustainability. ${ }^{6,7}$ A vegetarian or vegan diet can also be part of certain types of lifestyle and identity, ${ }^{8}$ or more healthrelated and part of a health intervention. ${ }^{4-6}$ The decision to use a vegetarian or vegan diet for health reasons might be strongly influenced by public perceptions of the health advantages, ${ }^{9}$ and a growing number of clinical and epidemiological research studies have shown health benefits associated with vegetarian and vegan diets. Results indicated that a vegetarian diet might be associated with a reduction in body weight, $^{10}$ a lower incidence of the metabolic syndrome ${ }^{11}$ or diabetes, ${ }^{11}$ 
improvements in blood pressure $\mathrm{e}^{12}$ and dyslipidemia ${ }^{13}$ and a lower incidence and/or mortality related to ischemic heart disease ${ }^{14}$ (indicating particular benefits for cardiovascular outcomes). ${ }^{11,15-19}$ Other studies also linked vegetarianism and veganism to a reduced incidence of cancer $^{14}$; however, a vegetarian, and especially vegan diet, might also be related to health risks including nutritional deficiencies such as vitamin B12, ${ }^{20}$ zinc, $^{21}$ and iron. ${ }^{22}$

To date few studies have investigated the prevalence of vegetarian and vegan nutrition. The reported prevalence rates have been highly variable, ranging from $0.77 \%$ in China $^{23}$ to $0.79 \%$ in Italy, ${ }^{24} 2.4 \%$ to $3.3 \%$ in the US, ${ }^{25,26}$ $3 \%$ to $8 \%$ in South Australia, ${ }^{27} 3.8 \%$ to $15.6 \%$ in Scandinavia, ${ }^{28}$ up to $33 \%$ in South Asia, ${ }^{25}$ and $36 \%$ in India. ${ }^{29}$ Whereas cultural and/or religious factors might substantially influence prevalence, methodological issues cannot be ruled out as contributing factors. Such issues relate to the definition and measurement of vegetarian diets (eg, self-identified, analyses of food frequency), or diversity of study samples (eg, age, area, socioeconomic status) among others, whereas some reports also lack a clear report of methodology. ${ }^{26}$ Last but not least, much research is older than a decade, ${ }^{25,27,28}$ although (primarily) plant-based forms of nutrition seem to have gained increasing popularity. ${ }^{30}$ These issues highlight the need for more recent, robust, and generalizable data on the prevalence of vegetarian forms of nutrition.

Given the potential implications of vegetarian and vegan nutrition on health and well-being, a better understanding of vegetarian and vegan diet use for health reasons is warranted. Thus this study aimed to identify prevalence and patterns of vegetarian and vegan diets for health reasons, and factors associated with vegetarian and vegan diet use for health reasons in a nationally representative US sample. The findings of this study will help inform future research, clinical practice, health policy, and public health initiatives.

\section{METHODS}

\section{Study Design}

The researchers performed a secondary analysis of 2012 US National Health Interview Survey data.

\section{Data}

This analysis was based on a nationally representative survey monitoring the health of the US population in 2012. ${ }^{31}$ For this analysis, data from the Family Core, the Sample Adult Core, and the Adult Complementary and Alternative Medicine questionnaire were used. The 2012 National Health Interview Survey was approved by the Research Ethics Review Board at the National Center for Health Statistics.

\section{Measures}

The Family Core and the Sample Adult Core questionnaire collected data regarding participants' sociodemographic characteristics, including age, gender, ethnicity, region, marital status, education, annual household income, and self-perceived general health status. The Adult Complementary and Alternative Medicine questionnaire collected data on the use of a number of interventions including special diets. Lifetime prevalence of health vegetarian or vegan diet use was determined with the following question: Have you ever used any of the following special diets for two weeks or more for health reasons: vegetarian, including vegan? Those who answered yes were presented with an additional question asking whether they had also used a vegetarian including vegan diet for health reasons during the past 12 months. They were further queried about whether they had ever seen a practitioner for special diets, and provided information on the frequency, costs, and health insurance coverage for those consultations.

Respondents who had used a vegetarian or vegan diet for health reasons in the past 12 months were asked their reasons for using such a diet, including general reasons and specific medical conditions (a total of 88 possible conditions), disclosure toward their personal health care provider or reasons for nondisclosure, perceived benefits of diet use, and information sources about vegetarian or vegan diet.

\section{Statistical Analyses}

A total of 42,366 households were eligible and 34,525 adults provided data (response rate of $79.7 \%$ ). ${ }^{32}$ Estimates were calculated using weights cali- brated to the 2010 Census-based population estimates for age, gender, and ethnicity of the US civilian noninstitutionalized population.

Prevalence of ever use and 12month use of vegetarian or vegan diet for health reasons were analyzed descriptively, as were details on vegetarian and vegan diet, reasons for practice, and outcomes. Results were reported as means and SDs, medians and ranges, weighted frequencies, and distributions, as were reasonable.

Sociodemographic characteristics were compared between those who had used a vegetarian or vegan diet ever in their life or within the prior 12 months and those who had not, using chisquare test. Factors independently associated with vegetarian or vegan diet use (ever used, used in the prior 12 months) were identified using multiple logistic regression analysis. The following sociodemographic variables were considered: age in years (18-29, $30-39,40-49,50-64$, or $\geq 65$ ), gender (female, male), ethnicity (non-Hispanic white, Hispanic, African American, Asian, or other), region (west, northeast, midwest, or south), marital status (not in relationship, in relationship), education (less than college, some college or more), and annual household income $(<\$ 20,000, \$ 20,000$ to $\$ 34,999, \$ 35,000$ to $\$ 64,999$ or $\geq \$ 65,000$ ). In addition, health-related factors such as general health status (excellent or very good, good, fair, or poor), body mass index $(<18.5-<25$, $25-<30$, or $\geq 30$ ), health behaviors such as smoking (nonsmoker, smoker), alcohol consumption (alcohol abstainer, light drinker, regular, or heavy drinker), and exercise behavior (lowlevel exerciser, moderate-level exerciser, or high-level exerciser); number of chronic medical conditions and diseases (none, 1, 2, or $\geq 3$ ); and health insurance (no health insurance, public health insurance, or private health insurance) were used as potential associated factors. These variables were chosen because they were shown to be associated with using other complementary therapies in the National Health Interview Survey. ${ }^{33-39}$

A backward stepwise procedure with a likelihood ratio statistic $P \leq .05$ was chosen and adjusted odds ratios with 95\% confidence intervals were calculated. Only those variables associated with vegetarian or vegan diet use at 
$P \leq .05$ (chi-square test) were included in the regression analyses. Statistical analysis was performed using the Statistical Package for Social Sciences software (release 22.0, IBM SPSS Statistics for Windows, IBM Corp, Armonk, NY, 2013).

\section{RESULTS}

A weighted total of 1,367 respondents had ever used a vegetarian or vegan diet for health reasons in their life (lifetime prevalence of $4.0 \%$ ), and 648 respondents had used this diet within the prior 12 months (12 month prevalence of $1.9 \%$ ).

Table 1 lists factors associated with ever use ( $R=.26$; multivariate coefficient $\left.\left[\mathrm{R}^{2}\right]=0.07\right)$ and 12-month use $\left(R=.24 ; \mathrm{R}^{2}=0.06\right)$ of vegetarian or vegan diet for health reasons in regression analyses. Associated factors were mostly congruent for ever use and 12month prevalence.

Of those who used vegetarian or vegan diets for health reasons in the past 12 months, $6.3 \%$ consulted with practitioners for special diets. Most of those knew the exact number of times they saw the practitioner (97.3\%), which was $2.9 \pm 2.8$ times on average (median, 2; range, 1-30). Costs for consultations were partly or fully covered by health insurance in $37.9 \%$ of cases; in half of those cases insurance covered the complete costs (50.8\%). Of those who had to pay consultation costs out of pocket, $61.1 \%$ were able to remember the exact costs for seeing the practitioner, which was US \$145.0 \pm \$160.7 on average (median, $\$ 150$; range, $\$ 0$ to $\$ 1,100)$.

Of all those who had used vegetarian or vegan diets for health reasons in the past 12 months, $18.3 \%$ had bought books or other material on vegetarian or vegan diets; the amount paid for such material was US $\$ 46.4 \pm \$ 47.2$ on average (median, \$30; range, $\$ 0$ to $\$ 200)$. Information about vegetarian and vegan diets was more frequently retrieved from the Internet (44.6\%); books, magazines, or newspapers (41.2\%); and health food stores (27.6\%).

Table 2 lists reasons for using a vegetarian or vegan diet, changes owing to a vegetarian or vegan diet, and disclosure to a personal health care provider among those for whom the vegetarian or vegan diet was among
Table 1. Independent Predictors of Ever Use and 12-Mo Use of Vegetarian or Vegan Diet for Health Reasons

\begin{tabular}{|c|c|c|}
\hline Predictor & $\begin{array}{l}\text { Ever Used Vegetarian/ } \\
\text { Vegan Diet Odds } \\
\text { Ratio (95\% Confidence } \\
\text { Interval); } P\end{array}$ & $\begin{array}{c}\text { Used Vegetarian/Vegan } \\
\text { Diet in Past } 12 \text { Mo Odds } \\
\text { Ratio } 95 \% \text { Confidence } \\
\text { Interval); } P\end{array}$ \\
\hline $\begin{array}{l}\text { Age, y } \\
\begin{array}{l}18-29 \\
30-39 \\
40-49 \\
50-64 \\
\geq 65\end{array}\end{array}$ & $\begin{array}{c}\text { Reference } \\
1.31(1.09-1.57) ; .004 \\
1.19(0.99-1.44) ; .07 \\
1.17(0.98-1.41) ; .09 \\
0.57(0.45-0.73) ;<.001\end{array}$ & $\begin{array}{c}\text { Reference } \\
1.48(1.13-1.93) ; .004 \\
1.35(1.03-1.78) ; .03 \\
1.55(1.20-2.01) ;<.001 \\
0.65(0.46-0.92) ; .02\end{array}$ \\
\hline $\begin{array}{l}\text { Gender } \\
\text { Male } \\
\text { Female }\end{array}$ & $\begin{array}{c}\text { Reference } \\
1.78(1.58-2.01) ;<.001\end{array}$ & $\begin{array}{c}\text { Reference } \\
1.68 \text { (1.41-2.00); <.001 }\end{array}$ \\
\hline $\begin{array}{l}\text { Ethnicity } \\
\text { Non-Hispanic white } \\
\text { Hispanic } \\
\text { Black } \\
\text { Asian } \\
\text { Other }\end{array}$ & $\begin{array}{c}\text { Reference } \\
0.72 \text { (0.59-0.88); .001 } \\
0.94 \text { (0.77-1.14); .60 } \\
1.19 \text { (0.96-1.46); .11 } \\
0.83 \text { (0.43-1.16); .66 }\end{array}$ & \\
\hline $\begin{array}{l}\text { US region } \\
\text { West } \\
\text { Northeast } \\
\text { Midwest } \\
\text { South }\end{array}$ & $\begin{array}{c}\text { Reference } \\
0.60(0.50-0.71) ;<.001 \\
0.63(0.54-0.74) ;<.001 \\
0.51(0.44-0.59) ;<.001\end{array}$ & $\begin{array}{c}\text { Reference } \\
0.65(0.54-0.87) ; .002 \\
0.73(0.59-0.91) ; .004 \\
0.46(0.37-0.57) ;<.001\end{array}$ \\
\hline $\begin{array}{l}\text { Education } \\
\text { Less than high school } \\
\text { At least high school } \\
\text { At least some college }\end{array}$ & $\begin{array}{c}\text { Reference } \\
1.93(1.48 ; 2.53) ;<.001 \\
3.68(2.81 ; 4.82) ;<.001\end{array}$ & $\begin{array}{c}\text { Reference } \\
1.64 \text { (1.16; 2.32); .005 } \\
2.82 \text { (1.99; 4.00); <.001 }\end{array}$ \\
\hline $\begin{array}{l}\text { Marital status } \\
\text { Not in relationship } \\
\text { In relationship }\end{array}$ & $\begin{array}{c}\text { Reference } \\
0.73(0.64-0.82) ;<.001\end{array}$ & $\begin{array}{c}\text { Reference } \\
0.65 \text { (0.55-0.77); <.001 }\end{array}$ \\
\hline $\begin{array}{l}\text { Body mass index } \\
\quad 18.5-<25 \\
\quad<18.5 \\
25-<30 \\
\geq 30\end{array}$ & $\begin{array}{c}\text { Reference } \\
1.15(0.79-1.69) ; .46 \\
0.86(0.75-0.99) ; .03 \\
0.61(0.52-0.71) ;<.001\end{array}$ & $\begin{array}{c}\text { Reference } \\
1.42(0.86-2.35) ; .21 \\
0.67(0.55-0.81) ;<.001 \\
0.58(0.47-0.72) ;<.001\end{array}$ \\
\hline $\begin{array}{l}\text { Chronic conditions, } \mathrm{n} \\
\text { None } \\
1 \\
2 \\
\geq 3\end{array}$ & $\begin{array}{c}\text { Reference } \\
1.20 \text { (1.04-1.39); .09 } \\
1.30 \text { (1.06-1.59); .02 } \\
1.44 \text { (1.12-1.85); .004 }\end{array}$ & $\begin{array}{c}\text { Reference } \\
1.42(1.17-1.74) ;<.001 \\
1.28(0.95-1.72) ; .12 \\
1.43(1.00-1.04) ; .06\end{array}$ \\
\hline $\begin{array}{l}\text { Smoking } \\
\text { Nonsmoking } \\
\text { Smoking }\end{array}$ & & $\begin{array}{c}\text { Reference } \\
0.67 \text { (0.52-0.86); .003 }\end{array}$ \\
\hline $\begin{array}{l}\text { Exercise intensity } \\
\text { Sedentary } \\
\text { Moderate intensity } \\
\text { High-level intensity }\end{array}$ & $\begin{array}{c}\text { Reference } \\
1.40(1.21-1.61) ;<.001 \\
1.52(1.20-1.92) ;<.001\end{array}$ & $\begin{array}{c}\text { Reference } \\
1.46(1.19-1.79) ;<.001 \\
1.29(0.90-1.84) ;<.001\end{array}$ \\
\hline $\begin{array}{l}\text { Health insurance } \\
\text { None } \\
\text { Public } \\
\text { Private }\end{array}$ & $\begin{array}{c}\text { Reference } \\
0.73(0.59-0.90) ; .003 \\
0.70 \text { (0.60-0.82); <.001 }\end{array}$ & $\begin{array}{c}\text { Reference } \\
0.75(0.56-1.01) ; .05 \\
0.66(0.53-0.82) ;<.001\end{array}$ \\
\hline
\end{tabular}

Notes: Regression output, included all predictors that were significant at $P<.05$. Data from the 2012 National Health Interview Survey were used (total sample: $N=34,525$; ever used vegetarian or vegan diet: $n=1,367$; used vegetarian or vegan diet in the past 12 months: $n=648$ ). 
Table 2. Health Reasons for Using Vegetarian or Vegan Diet, Changes Owing to Vegetarian or Vegan Diet, and Disclosure to Personal Health Care Provider

\section{Items}

Reasons to use vegetarian or vegan diet $^{a}$

General wellness or general disease prevention

Improve energy

Improve athletic or sports performance

Improve immune function

Improve memory or concentration

Using a vegetarian/vegan diet motivate to ...

Eat healthier

Exercise more regularly

Cut back or stop drinking alcohol

Cut back or stop smoking cigarettes

Eat more organic food

Respondents (\%)

Using a vegetarian or vegan diet lead to ...

Give a sense of control over health

75.4

57.6

23.8

50.6

27.6

Help reduce stress level or relax

78.4

38.6

19.3

30.4

60.4

Help sleep better

Helps feel better emotionally

Make it easier to cope with health problems

68.3

43.1

42.1

53.5

Improve overall health and make you feel better

45.9

Improve your relationships with others

76.4

29.3

Improve attendance at job or school

25.4

How important was using a vegetarian or vegan diet for maintaining health and well-being ${ }^{b}$

Very important

58.2

Somewhat important

26.3

Slightly important

7.8

Not at all important

5.1

Used a vegetarian or vegan diet for a specific health problem (top health problem)

Specific health problems: ${ }^{2}$

High cholesterol

24.7

Problems with being overweight

23.1

Hypertension

13.4

Diabetes

13.1

Stomach or intestinal illness

8.9

Joint pain or stiffness

8.6

Using a vegetarian/vegan diet helped for specific health problem ...'

A great deal

59.0

Some

26.3

Only a little

9.1

Not at all

2.0

Received the following for a specific health problem (for which a vegetarian or vegan diet was used ${ }^{b}$

Prescription medication

47.1

Over-the-counter medication

20.8

Surgery

Physical therapy

7.3

Mental health counseling

7.7

7.5

Vegetarian or vegan diet was used because ...

Medical treatments were too expensive

12.5

Therapy combined with medical treatment would help the top 3 complementary medicine interventions.

\section{DISCUSSION}

Several findings of this study deserve attention. First, this study found that the prevalence of health vegetarianism (including health veganism) in this nationally representative sample was $1.9 \%$ in 2012 , which was an $18.8 \%$ increase from 2002. ${ }^{40}$ However, it was considerably lower than prevalence rates reported in previous studies. ${ }^{25,26}$ This might be related to the presentation of questions in the instrument itself: Participants were asked whether they had followed a vegetarian or vegan diet for health reasons, which might have led to nonresponse in those who had followed such a diet for ethical instead of health reasons. The difference in prevalence may also be related to the area in which the surveys were conducted, because the current analysis showed significant associations in the use of vegetarian diets and living in the western US region. Another study found that an estimated $10.0 \%$ of the US population followed a vegetarianinclined diet, which is a diet focusing on plant-based nutrition while keeping meat consumption to a minimum, ${ }^{41}$ which was not considered in the current survey.

Another finding was the rate at which health vegetarians or vegans consulted with a practitioner for special diets. Contrary to practitionerbased interventions, ${ }^{42}$ there was no need to see a health care provider for dietary changes, and vast information on vegetarian and vegan diets can be found online and in health food stores and self-care and recipe books. Apart from the cost related to exotic food items and/or food supplementation, this makes the vegetarian diet a potentially economic self-care intervention with assumed health benefits.

Nevertheless the unsupervised use of any diet might bear some risks in healthy people as well as in users with underlying medical conditions. Although this study found that a large percentage reported using vegetarian or vegan diets for general health and well-being and prevention rather than specific conditions, a substantial amount used it to treat medical conditions such as 
Table 2. Continued

\section{Items}

Medical treatments do not work for your specific health problem

Medications cause side effects

It can be practiced on your own

It is natural

It focuses on the whole person, mind, body, and spirit

It treats the cause and not just the symptoms

It was part of your upbringing

Vegetarian or vegan diet was recommended by ...

\section{Medical doctor}

Family member

Friend

Coworker

Vegetarian or vegan diet was disclosed to personal health care provider ${ }^{\mathrm{b}}$

Not disclosed because ... ${ }^{a}$

Not used at the time

They discouraged use of it in the past

Was worried they would discourage it

Was concerned about a negative reaction

Did not think they needed to know

They did not ask

Did not think they know as much about it as you do

They did not give enough time to tell them

Information sources on vegetarian and vegan diets ${ }^{a}$

Internet

Books, magazines, or newspapers

DVDs, videos, or CDs

Television or radio

Scientific articles

Health food stores

${ }^{a}$ Multiple responses were allowed; ${ }^{\mathrm{b}}$ Single-choice answer.

Note: Data from the 2012 National Health Interview Survey were used (respondents used a vegetarian or vegan diet in the past 12 months; $n=648$ ).

overweight, hypertension, hypoglycemia, and high cholesterol. A vegetarian diet is generally considered beneficial for those conditions. ${ }^{43,44}$ Overall, most US vegetarians eat fruits and vegetables more frequently and highly processed, highly saturated fat and sugar convenience products less frequently than do non-vegetarians; however, South Asian vegetarians consume unhealthy convenience products more often. ${ }^{25}$ Thus, whether a vegetarian diet is beneficial for metabolic conditions might also depend on culturally influenced food choices. Although a strict or unbalanced vegetarian diet might lead further to nutritional deficiencies, such as vitamin $\mathrm{B}_{12}$ or $\mathrm{D}$ or minerals such as calcium and zinc, ${ }^{45,46}$ this is also the case for other, non-vegetarian diets. ${ }^{46}$ There- fore, whereas for most healthy adults a transition to plant-based nutrition might not be of concern, adults with underlying medical conditions or those with eating disorders might generally benefit from consulting with their health care providers before changing their diet.

A finding closely related to this is that $40 \%$ of healthy vegetarians and vegans did not disclose the practice to their health care provider. This is even more problematic because a large proportion of respondents indicated that they used a vegetarian or vegan diet because their medical treatment had side effects, and they assumed the vegetarian diet would be a good addition to their current therapy. Nondisclosure also does not seem to be related to anticipated negative reactions rather than the fact that the provider did not ask, which highlights the importance of provider-initiated enquiries. Especially in patients with medical conditions that require drug therapy, it is essential that communication includes the use of special diets, because this might severely affect the efficacy and safety of medical interventions. Studies showed that the use of vegetarian diets might be associated with decreasing blood pressure, blood sugar, and blood lipid levels, ${ }^{43,44}$ and such changes may actually require drug therapy adjustments. However, this would require trained and experienced health care providers who are knowledgeable about special diets and their impact on human health, and whose advice is trusted by patients.

Another finding from this study is that the use of a vegetarian diet for health reasons is associated with other health behaviors, including not smoking and regular physical activity, which indicates that vegetarian and vegan diets may be part of an overall healthy lifestyle. In terms of risk factors for health in general and cardiovascular in particular, not smoking, eating a balanced and healthy diet, and following a physically active lifestyle are among the most important and effective strategies to decreasing the risk of lifestylerelated conditions, ${ }^{11,12,14-19,25,47,48}$ and are regularly recommended. A growing number of clinical and epidemiological research studies showed health benefits associated with vegetarian and vegan diets, especially regarding cardiovascular health ${ }^{10-13,14-19}$ and cancer, ${ }^{19,49}$ which makes vegetarian and vegan diets an important method to improve health and well-being and prevent chronic lifestyle-associated diseases.

Nonetheless, the findings identified through this analysis must be considered in light of the study limitations. Limitations of this study include the fact that participants were asked whether they had used this diet for health reasons, thus neglecting the use of vegetarian or vegan diets for ethical or environmental reasons. Another drawback resulted from the formulation of the question, which asked whether a vegetarian or vegan diet was used for at least 2 weeks in a given time, and resulted in a raw estimate of diet users. The data were drawn from a crosssectional survey; as such, the results only suggest association, not causation. 
The interpretations that can be drawn from the findings are strengthened, however, by the regression analysis that controlled for confounding variables. No adjustment for multiple testing in the regression analyses was used. It has been shown that without a correction, the overall Type I error rate may be inflated, depending on the number of predictors. Nevertheless, this approach was chosen because corrections for multiple testing in regression analyses commonly are overly conservative and inflate Type II error rates. $^{33}$ It should be kept in mind, though, that the results of the regression analyses might contain some variables that are not actually needed in the model. The $\mathrm{R}^{2}$ values were low, which could be interpreted as a relatively low amount of explained variance. However, in contrast to linear regressions, low $\mathrm{R}^{2}$ values are the norm in logistic regression and their use in interpreting the goodness of fit of the regression model is generally discouraged. $^{34}$ The survey was collected by self-report and as such is at risk of recall bias or measurement error. Nonetheless, the US National Health Survey is an internationally recognized epidemiological study and its findings provide useful insights into the use of vegetarian and vegan diets.

\section{Implications for Research and Practice}

The findings of this analysis have implications for future studies and health care. Missing from this survey was the assessment of whether individuals minimally consume meat and/or follow a full plant-based diet for reasons other than health. About $10.0 \%$ of the US population follows a diet focusing on plant-based nutrition with minimal meat consumption. ${ }^{41}$ The prevalence of following this form of diet for health reasons and its perceived health benefits warrant further investigation. Thus, future studies might provide more details on the use of vegetarian and vegan diets, including limited use vs full-time use and complete meat abstinence vs vegetarian-inclined diets among other factors. To exploit the vegetarian and vegan diets' full potential for prevention and condition management, further studies are warranted to examine their efficacy and safety in general, and in specific medical condi- tions in particular. Given the abundance of health advice and dietary advice available from the Internet, magazines, and health food stores, which is not necessarily based on scientific evidence, ${ }^{50}$ the integration of diet and nutrition into health care delivery warrants further attention.

\section{REFERENCES}

1. Craig WJ, Mangels AR, American Dietetic Association. Position of the American Dietetic Association: vegetarian diets. J Am Diet Assoc. 2009;109: 1266-1282.

2. Academy of Nutrition and Dietetics. Vegetarian Nutrition. Evidence-based Practice Guideline 2016. http://www. andeal.org/topic. cfm?menu=5271\&pcat= 4023\&cat $=5450$. Accessed April 20, 2017.

3. NutritionFacts.org | The Latest in Nutrition Related Research. http:// nutritionfacts.org. Accessed April 20, 2017.

4. Kessler CS, Holler S, Joy S, et al. Personality profiles, values and empathy: differences between lacto-ovo-vegetarians and vegans. Forsch Komplementmed. 2016;23: 95-102.

5. Ruby MB. Vegetarianism: a blossoming field of study. Appetite. 2012;58:141-150.

6. Fox N, Ward K. Health, ethics and environment: a qualitative study of vegetarian motivations. Appetite. 2008; 50:422-429.

7. Ruby MB, Heine SJ, Kamble S, Cheng TK, Waddar M. Compassion and contamination: cultural differences in vegetarianism. Appetite. 2013;71:340-348.

8. Fox N, Ward KJ. You are what you eat? Vegetarianism, health and identify. Soc Sci Med. 2008;66:2585-2595.

9. Lea EJ, Crawford D, Worsley A. Public views of the benefits and barriers to the consumption of a plant-based diet. Eur J Clin Nutr. 2006;60:828-837.

10. Huang RY, Huang CC, Hu FB, Chavarro JE. Vegetarian diets and weight reduction: a meta-analysis of randomized controlled rrials. J Gen Intern Med. 2016;31:109-116.

11. Orlich MJ, Fraser GE. Vegetarian diets in the Adventist Health Study 2: a review of initial published findings. Am J Clin Nutr. 2014;100(suppl 1):353S-358S.

12. Yokoyama Y, Nishimura K, Barnard ND, et al. Vegetarian diets and blood pressure: a meta-analysis. JAMA Intern Med. 2014;174:577-587.

13. Wang F, Zheng J, Yang B, Jiang J, Fu Y, Li D. Effects of vegetarian diets on blood lipids: a systematic review and metaanalysis of randomized controlled trials. J Am Heart Assoc. 2015;4:e002408.

14. Dinu M, Abbate R, Gensini GF, Casini A, Sofi F. Vegetarian, vegan diets and multiple health outcomes: a systematic review with meta-analysis of observational studies. Crit Rev Food Sci Nutr. 2017;57:3640-3649.

15. Muller DC, Murphy N, Johansson M, et al. Modifiable causes of premature death in middle-age in Western Europe: results from the EPIC cohort study. BMC Med. 2016;14:87.

16. Orlich MJ, Singh PN, Sabate J, et al. Vegetarian dietary patterns and mortality in Adventist Health Study 2. JAMA Intern Med. 2013;173:1230-1238.

17. Appleby PN, Crowe FL, Bradbury KE, Travis RC, Key TJ. Mortality in vegetarians and comparable nonvegetarians in the United Kingdom. Am J Clin Nutr. 2016;103:218-230.

18. Schmidt JA, Rinaldi S, Ferrari P, et al. Metabolic profiles of male meat eaters, fish eaters, vegetarians, and vegans from the EPIC-Oxford cohort. Am J Clin Nutr. 2015;102:1518-1526.

19. Appleby PN, Key TJ. The long-term health of vegetarians and vegans. Proc Nutr Soc. 2016;75:287-293.

20. Pawlak R, Lester SE, Babatunde T. The prevalence of cobalamin deficiency among vegetarians assessed by serum vitamin B12: a review of literature. Eur J Clin Nutr. 2014;68:541-548.

21. Foster M, Chu A, Petocz P, Samman S. Effect of vegetarian diets on zinc status: a systematic review and meta-analysis of studies in humans. J Sci Food Agric. 2013;93:2362-2371.

22. Jackson J, Williams R, McEvoy M, MacDonald-Wicks L, Patterson A. Is higher consumption of animal flesh foods associated with better iron status among adults in developed countries? A systematic review. Nutrients. 2016;8: 89.

23. Mao X, Shen X, Tang W, et al. [Prevalence of vegetarians and vegetarian's health dietary behavior survey in Shanghai]. Wei Sheng Yan Jiu. 2015;44:237-241.

24. Ponzio E, Mazzarini G, Gasperi G, Bottoni MC, Vallorani S. The vegetarian habit in Italy: prevalence and characteristics of consumers. Ecol Food Nutr. 2015;54:370-379.

25. Jaacks LM, Kapoor D, Singh K, et al. Vegetarianism and cardiometabolic disease risk factors: differences between South Asian and US adults. Nutrition. 2016;32:975-984. 
26. The Vegetarian Resource Group. How many adult vegetarians in the U.S.? http://www.vrg.org/press/201511press.htm. Accessed April 20, 2017.

27. Worsley A, Skrzypiec G. Teenage vegetarianism: prevalence, social and cognitive contexts. Appetite. 1998;30:151-170.

28. Larsson CL, Klock KS, Astrom AN, Haugejorden O, Johansson G. Food habits of young Swedish and Norwegian vegetarians and omnivores. Public Health Nutr. 2001;4:1005-1014.

29. Agrawal S, Millett CJ, Dhillon PK, Subramanian SV, Ebrahim S. Type of vegetarian diet, obesity and diabetes in adult Indian population. Nutr J. 2014; 13:89.

30. Kessler CS, Michalsen A. Veg* in der Medizin-schon langst viel mehr als nur ein Trend [in German]. Forsch Komplementmed. 2016;23:64-65.

31. Centers for Disease Control and Prevention. National Health Interview Survey. https://www.cdc.gov/nchs/nhis/. Accessed April 20, 2017.

32. Blackwell DL, Lucas JW, Clarke TC. Summary health statistics for U.S. adults: national health interview survey, 2012. Vital Health Stat 10. 2014;(260):1-161.

33. Perrett DJ, Schaffer J, Piccone A, Roozeboom M. Bonferroni adjustments in tests for regression coefficients. Multiple Linear Regression Viewpoints. 2006;32:1-6.

34. Hosmer DW, Lemeshow S. Applied Logistic Regression.. New York, NY: Wiley-Interscience; 2000.

35. Falci L, Shi Z, Greenlee H. Multiple chronic conditions and use of complementary and alternative medicine among US adults: results from the 2012 National
Health Interview Survey. Prev Chronic Dis. 2016;13:E61.

36. Rhee TG, Evans RL, McAlpine DD, Johnson PJ. Racial/ethnic differences in the use of complementary and alternative medicine in US adults with moderate mental distress: results from the 2012 National Health Interview Survey. J Prim Care Community Health. 2017;8:43-54.

37. Cramer H, Hall H, Leach M, et al. Prevalence, patterns, and predictors of meditation use among US adults: a nationally representative survey. Sci Rep. 2016;10:36760.

38. Cramer H, Ward L, Steel A, Lauche R, Dobos G, Zhang Y. Prevalence, patterns, and predictors of yoga use: results of a U.S. nationally representative survey. Am J Prev Med. 2016;50:230-235.

39. Lauche R, Wayne PM, Dobos G, Cramer H. Prevalence, patterns, and predictors of t'ai chi and qigong use in the United States: results of a nationally representative survey. J Altern Complement Med. 2016;22:336-342.

40. Barnes PM, Powell-Griner E, McFann K, Nahin RL. Complementary and alternative medicine use among adults: United States, 2002. Adv Data. 2004;(343):1-19.

41. Vegetarian Times. Vegetarianism in America. http://www.vegetariantimes. com/article/vegetarianism-in-america/. Accessed April 20, 2017.

42. Zhang Y, Leach MJ, Bishop FL, Leung B. A comparison of the characteristics of acupuncture- and non-acupuncture-preferred consumers: a secondary analysis of NHIS 2012 data. J Altern Complement Med. 2016;22:315-322.
43. Chiu YF, Hsu CC, Chiu TH, et al. Cross-sectional and longitudinal comparisons of metabolic profiles between vegetarian and non-vegetarian subjects: a matched cohort study. Br J Nutr. 2015; 114:1313-1320.

44. Sabate J, Wien M. A perspective on vegetarian dietary patterns and risk of metabolic syndrome. Br J Nutr. 2015; 113(suppl 2):S136-S143.

45. Elorinne AL, Alfthan G, Erlund I, et al. Food and nutrient intake and nutritional status of Finnish vegans and non-vegetarians. PLoS One. 2016;11: e0148235.

46. Schupbach R, Wegmuller R, Berguerand C, Bui M, Herter-Aeberli I. Micronutrient status and intake in omnivores, vegetarians and vegans in Switzerland. Eur J Nutr. 2017;56:283-293.

47. Kang SJ, Kim EH, Ko KJ. Effects of aerobic exercise on the resting heart rate, physical fitness, and arterial stiffness of female patients with metabolic syndrome. J Phys Ther Sci. 2016;28: 1764-1768.

48. Lee YM, Kim SA, Lee IK, et al. Effect of a brown rice based vegan diet and conventional diabetic diet on glycemic control of patients with type 2 diabetes: a 12-week randomized clinical trial. PLoS One. 2016;11:e0155918.

49. Orlich MJ, Singh PN, Sabate J, et al. Vegetarian dietary patterns and the risk of colorectal cancers. JAMA Intern Med. 2015;175:767-776.

50. Alnemer KA, Alhuzaim WM, Alnemer AA, et al. Are health-related tweets evidence based? Review and analysis of health-related tweets on Twitter. J Med Internet Res. 2015;17. e246. 


\section{CONFLICT OF INTEREST}

The authors have not stated any conflicts of interest. 